\title{
In Vitro Characterization of Docetaxel as a Radiosensitizer in Canine and Feline Cancer Cell Lines
}

\author{
Cheryl E. Balkman ${ }^{1}$, Tracy L. Gieger ${ }^{1}$, Marsha M. Zgola ${ }^{1}$, Lionel D. Lewis ${ }^{2}$, Margaret C. McEntee ${ }^{1}$ \\ ${ }^{1}$ Department of Clinical Sciences, College of Veterinary Medicine, Cornell University, Ithaca, USA \\ ${ }^{2}$ Department of Medicine, The Geisel School of Medicine at Dartmouth and Dartmouth-Hitchcock Medical Center, \\ Lebanon, USA \\ Email:mcm43@cornell.edu
}

Received August 29, 2012; revised September 27, 2012; accepted October 10, 2012

\begin{abstract}
An in vitro study was conducted to investigate docetaxel as a radiation sensitizer in four canine (mammary carcinomaCMT12 and CMT25, osteosarcoma-OS2.4, and transitional cell carcinoma-PTCC), and one feline cancer cell line (oral squamous cell carcinoma-SCCF1) to provide a basis for combination therapy in clinical patients. Cells were exposed to docetaxel followed by a single dose of radiation. The percent surviving fraction was determined by MTT assay. The combination index (CI) method determined synergistic cytotoxicity for the CMT12, CMT25 and OS2.4 cell lines with median CI values of $0.35,0.47,0.63$ respectively. The SCCF1 cell line had moderate synergistic cytotoxicity with a median CI of 0.76 , while the PTCC cell line resulted in antagonistic cytoxicity with a median CI of 2.75 . The results indicated that docetaxel was a radiation sensitizer in 4 out of the 5 cancer cell lines tested.
\end{abstract}

Keywords: Docetaxel; Chemotherapy; Radiation Therapy; In Vitro

\section{Introduction}

Chemoradiotherapy, with administration of chemotherapeutic agents prior to and during the course of radiation therapy, is increasingly being used in veterinary cancer therapy 1) as a radiation sensitizer, to improve the response to local radiation; 2) for the treatment of advanced locoregional disease; and/or 3) for both local as well as systemic effects on those tumors with a high metastatic potential [1-7]. The clinical investigation of combination chemotherapy and radiation therapy in veterinary medicine has historically been limited to retrospective observational studies. A coordinated and scientific approach to the advancement of combination therapy in the clinic mandates preliminary in vitro studies of the combined cytotoxicity of chemotherapeutic agents and radiation. In order to realize improvements in response to radiation therapy it is preferable to combine it with a chemotherapeutic agent that has proven efficacy in the treatment of the tumor type under investigation. Additionally, the chemotherapeutic agent must have a potentiating effect or exhibit enhancement of the radiation response in the tumor that is greater than the enhancement of local normal tissue toxicity, thus achieving the goal of increasing the therapeutic index. It is also necessary to determine how best to combine radiation and chemotherapy, specifically in reference to scheduling and dosing of chemotherapy relative to the radiation therapy.
The current literature reveals a relative paucity of in vitro investigations of chemosensitivity in veterinary oncology for conventional chemotherapeutics [8-13].

Docetaxel is a semisynthetic taxane whose primary mechanism of cytotoxicity is enhanced tubulin polymerization and inhibition of microtubule depolymerization [14]. The initial rationale for using docetaxel as a radiation enhancer is that taxanes arrest proliferating cells in the $\mathrm{G}_{2} \mathrm{M}$ phase of the cell cycle which is the most radiosensitive cell cycle phase [15]. The reason for this differential-phase sensitivity is that the endogenous radioprotectors, molecules containing sulfhydryl groups, are at their lowest concentrations in the cell during $\mathrm{G}_{2} \mathrm{M}$. Sulfhydryl-group mediated cytoprotection results from both free-radical scavenging that protects against oxygen freeradical generation by ionizing radiation, and hydrogenatom donation to facilitate direct repair at sites of DNA damage. Docetaxel induces mitotic arrest and apoptosis in a concentration-dependent fashion and at low concentration can induce apoptosis without $\mathrm{G}_{2} \mathrm{M}$ arrest [16-18]. Other mechanisms have been elucidated that may contribute to enhanced cytotoxicity in combination with radiation including: 1) the ability of docetaxel to eliminate radioresistant S-phase cells; 2) the ability of docetaxel to cause tumor reoxygenation; 3 ) the stimulation of antitumor immune resistance mechanisms; and 4) the inhibition of tumor angiogenesis at low docetaxel concentra- 
tions by inhibiting endothelial cell proliferation, migration and differentiation [19-21]. An additional attribute of docetaxel is that it does not activate the orphan nuclear receptor SXR which is critical in the development of drug resistance, whereas paclitaxel has been shown to activate SXR and enhance ABCB-1 (MDR1, P-glycoprotein [P-gp]) mediated drug efflux [22]. Docetaxel has been shown to have a radiosensitizing effect in vitro in human colon, lung, head and neck and cervical cancer cell lines $[15,20,23,24]$. Furthermore, docetaxel has been shown to increase the therapeutic index when combined with radiation therapy in vivo in murine human xenograft cancer models as well as Phase I/II trials in humans with advanced cancer [25-28].

Alternative schedules of administration of docetaxel have been investigated that complement the use of docetaxel in combination with radiation therapy and are distinct from the scheduling of single agent docetaxel $[29,30]$. Based on these in vitro schedules, docetaxel has proven effective in clinical trials involving humans with head and neck carcinoma treated with combination radiation therapy with weekly docetaxel and a Phase I/II docetaxel plus concurrent hyperfractionated radiotherapy in locally advanced unresectable head and neck cancer (TAX.ES1.102 study) [27,28,31-33].

Our long term goal is to define the role of docetaxel (DT) as a radiation sensitizer in the treatment of canine and feline cancer. Previously reported, phase I dose escalation studies in dogs and cats with spontaneous tumors determined the maximally tolerated dose of oral docetaxel $[34,35]$. A phase II study to determine the efficacy of oral docetaxel in the management of canine epithelial tumors has been completed. In this study canine oral squamous cell carcinoma was found to be responsive to oral docetaxel [36]. Furthermore a phase II study to determine the efficacy of oral docetaxel in the management of feline epithelial tumors targeting oral squamous cell carcinoma is currently ongoing.

The current series of in vitro experiments was performed to investigate the hypothesis that docetaxel would synergistically enhance the cytotoxicity of radiation therapy in canine and feline cancer cell lines in vitro. If this hypothesis was confirmed the studies would provide a basis for combination therapy of docetaxel plus radiation in the veterinary oncology clinic. In order to test this hypothesis we performed in vitro studies of the cytotoxicity of radiation therapy alone, docetaxel alone and then varying concentrations of docetaxel combined with a range of radiation exposures against different canine and feline cancer cell lines.

\section{Materials and Methods}

\subsection{Canine and Feline Tumor Cell Lines}

Canine mammary carcinoma cell lines (CMT12 and
CMT25) were provided by Allison Church Bird, Auburn University College of Veterinary Medicine, Auburn, AL 36849. The canine osteosarcoma cell line (OS2.4) was provided by Dr. Katrina Mealey, Washington State University College of Veterinary Medicine, Pullman, WA 99164. The canine transitional cell carcinoma cell line (PTCC) was provided by Dr. Deborah Knapp, Purdue University College of Veterinary Medicine, WestLafayette, IN 47907. The feline oral squamous cell carcinoma (SCC) cell line (SCCF1) was provided by Dr. Thomas Rosol, The Ohio State University College of Veterinary Medicine, Columbus, OH 43210.

The canine mammary carcinoma cells were grown in Leibovitz L-15 media supplemented with $2.0 \mathrm{mM}$ glutamine, $1 \mathrm{mM}$ sodium pyruvate, $10 \mathrm{mM}$ HEPES buffer, and $0.15 \%$ sodium bicarbonate solution (Invitrogen Inc. Carlsbad, CA, USA). The canine transitional cell carcinoma and osteosarcoma cell lines were grown in RPMI 1640 (Invitrogen Inc. Carlsbad, CA, USA). The feline SCC cells were grown in DMEM high glucose media (Dulbecco's modified eagle medium, Invitrogen Inc. Carlsbad, CA, USA). All media were supplemented with $10 \%$ fetal bovine serum and a $1 \%$ antibiotic/antimycotic solution (consisting of $100 \mathrm{U}$ penicillin/100 ug streptomycin/0.25 $\mu \mathrm{g}$ amphotericin B per milliliter of media) (Invitrogen Inc. Carlsbad, CA, USA). All cell lines were maintained in a humidified atmosphere of $95 \%$ Air $/ 5 \%$ $\mathrm{CO}_{2}$ and incubated at $37^{\circ} \mathrm{C}$.

Cells were seeded in triplicate at $2-5 \times 10^{4}$ cells per well depending on the cell type into 96 well microtiter plates in a fixed volume of $100 \mu \mathrm{l}$ of complete media and incubated overnight in a humidified atmosphere of $95 \%$ Air $/ 5 \% \mathrm{CO}_{2}$ at $37^{\circ} \mathrm{C}$ to allow cell attachment prior to experimental conditions.

\subsection{Docetaxel}

Docetaxel (Taxotere ${ }^{\mathrm{TM}}$ ), was obtained from Aventis Pharmaceuticals Products Inc., (Collegeville, PA) and prepared as described on the package insert. The initial docetaxel stock solution in ethanol was stored at $-80^{\circ} \mathrm{C}$. Immediately prior to each experiment the docetaxel was thawed and diluted with culture medium to the final concentrations to be used in the cytotoxicity experiments. The final concentration of ethanol and polysorbate 80 in the culture media used in experiments never exceeded $0.1 \%$ and $0.0025 \%$ respectively.

Twenty-four hours after seeding into 96 well microtiter plates the complete medium was replaced with fresh serum-free medium alone or serum-free medium containing docetaxel at concentrations ranging from $0-100$ $\mu \mathrm{M}$ for 4 hours in a humidified atmosphere of $95 \%$ Air $/ 5 \% \mathrm{CO}_{2}$ at $37^{\circ} \mathrm{C}$. Following incubation this medium was removed and the cells washed with HBSS (Hank's Balanced Salt Solution, Invitrogen Inc. Carlsbad, CA, 
USA) and fresh complete medium was added. Cells were either incubated without further treatment or irradiated as described below. Untreated controls and cells treated with radiation only were also sham-treated by rinsing with HBSS.

\subsection{Radiation}

Irradiation of the cell lines was performed using a standard procedure. A Siemens $6 \mathrm{MV}$ linear accelerator was used to deliver radiation at a dose rate of $200 \mathrm{cGy} /$ minute. Plated cells were irradiated under conditions of full dose buildup with $1.5 \mathrm{~cm}$ of tissue equivalent bolus material placed in the path of the radiation beam and with the gantry of the linear accelerator at $180^{\circ}$. The cells were exposed to a single radiation dose which ranged from 0 to 10 Gy in 2 Gy increments after which they were incubated in a humidified atmosphere of $95 \%$ Air $/ 5 \% \mathrm{CO}_{2}$ at $37^{\circ} \mathrm{C}$ for 72 hours.

\subsection{Cell Viability Assay}

An MTT assay was performed 72 hours after experimental conditions described above. Briefly, the cells were incubated at $37^{\circ} \mathrm{C}$ for one hour in $180 \mu$ l of serum-free RPMI 1640 media without phenol red and $20 \mu \mathrm{l}$ of $5 \mathrm{mg} / \mathrm{ml}$ MTT solution (Sigma-Aldrich, St Louis, Mo). The supernatants were removed and $200 \mu 1$ of 2-propanol was added to each well to stop the MTT reaction. The cells were solubilized with repeat pipetting within the plate and absorbance readings were performed on a Tecan Safire microplate reader (Tecan, Raleigh, NC, USA) using a measurement wavelength of $540 \mathrm{~nm}$ and reference wavelength of $630 \mathrm{~nm}$.

\subsection{Analysis of the Combination Effects of Docetaxel with Radiation and Statistical Methods}

The determination of cytotoxic activity of the combination of docetaxel and radiation was done using the combination index (CI) method of Chou-Talalay [37,38]. The general equation for the classic isobologram is given by:

$$
\mathrm{CI}=(\mathrm{D})_{1} /\left(\mathrm{D}_{\mathrm{x}}\right)_{1}+(\mathrm{D})_{2} /(\mathrm{Dx})_{2}
$$

where $\left(D_{x}\right)_{1}$ and $\left(D_{x}\right)_{2}$ in the denominators are the concentrations/doses for $\mathrm{D}_{1}$ (docetaxel) and $\mathrm{D}_{2}$ (radiation) alone that give $\mathrm{x} \%$ inhibition, whereas $(\mathrm{D})_{1}$ and $(\mathrm{D})_{2}$ in the numerators are the concentrations/doses of docetaxel and radiation in combination that also inhibit $\mathrm{x} \%$ (i.e., isoeffect). The $\left(D_{x}\right)_{1}$ or $\left(D_{x}\right)_{2}$ for docetaxel and radiation can be readily calculated from the median-effect equation of Chou [39]:

$$
D_{x}=D_{m} \cdot\left[f_{a} / 1-f_{a}\right]^{1 / m}
$$

where $f_{a}$ is the fraction affected and $D_{m}$ is the median effect concentration or dose $\left(\mathrm{IC}_{50}\right.$ or $\left.\mathrm{ID}_{50}\right)$ that is obtained from the antilog of the $\mathrm{X}$-intercept of the median effect plot, $X-\log (D)$ versus $Y=\log \left[f_{a} /\left(1-f_{a}\right)\right]$ or $D_{m}=$ $10^{-(\mathrm{y} \text {-intercet }) / \mathrm{m}}$, and $\mathrm{m}$ is the slope of the median effect plot. For conservative mutually nonexclusive isobolograms of two agents, a third term is added. The third term is usually omitted, when the mutually exclusive $(\alpha=0)$ assumption or classic isobologram is used $[37,38]$ :

$$
\alpha(\mathrm{D})_{1}(\mathrm{D})_{2} /(\mathrm{Dx})_{1}(\mathrm{Dx})_{2}
$$

The software program "Calcusyn" (Biosoft ${ }^{\mathrm{TM}}$, Cambridge, UK and USA) was used to perform these analyses and create a CI-isobologram for each combination. Graphical representations of the data from this analysis were generated with the CI on the y-axis and the $f a$ (fraction of effect affected i.e. the CI for a particular \% cell death e.g. 0.3 for $30 \%$ ) on the x-axis. A CI value between 0.9 and 1.1 indicates only additivity. Moderate synergism is depicted by CI values between 0.7 and 0.9 and clear synergism by CI values below 0.7. Antagonism is depicted by CI values above 1.1 .

\section{Results}

\section{Cytotoxic Effects of Docetaxel, Radiation, and Docetaxel Combined with Radiation}

Docetaxel was cytotoxic to all cell lines in a concentration dependent manner (Figure 1) with an $\mathrm{EC}_{50}$ which ranged from $0.3-5.3 \mu \mathrm{M}$, depending on the cancer cell line. All the cell lines were relatively resistant to the cytotoxic effects of a single radiation exposure of up to 10 Gy (Figure 2) with the $\mathrm{ID}_{50}(5.7 \mathrm{~Gy})$ only being defined for OS 2.4 cells. To determine whether the combination of docetaxel and radiation therapy resulted in synergistic cytotoxicity, the combination index was determined for each cell line. The combination of docetaxel and radiation resulted in synergistic cytoxicity for all cancer cell lines tested (Table 1 and Figures 3(a)-(d) for CI) with the exception of the transitional cell carcinoma cell line (PTCC) in which it showed antagonistic cytotoxicity, with a median CI of 2.75 (Figure 3(e)).

\section{Discussion}

Docetaxel's potential as a radiation sensitizer in veterinary patients with carcinomas/sarcomas was investigated in 4 animal carcinoma cell lines ( 3 canine, and 1 feline) and 1 canine osteosarcoma cell line. Cell viability was assessed using the MTT assay in control cells, cells exposed to docetaxel or radiation alone and cells exposed to docetaxel followed/combined with a single dose of radiation. Exposure to docetaxel alone resulted in concentration 


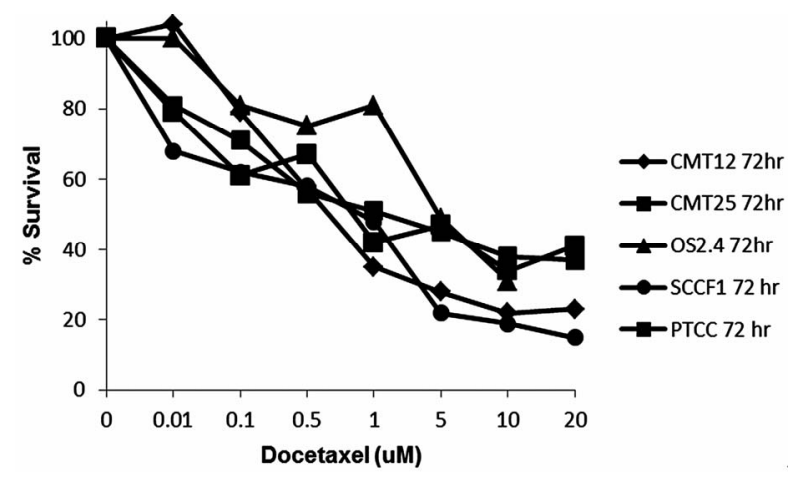

Figure 1. Concentration of docetaxel (uM) versus \% surviving fraction (as measured by MTT assay) for the cancer cell lines CMT12, CMT25, OS2.4, SCCF1 and PTCC.

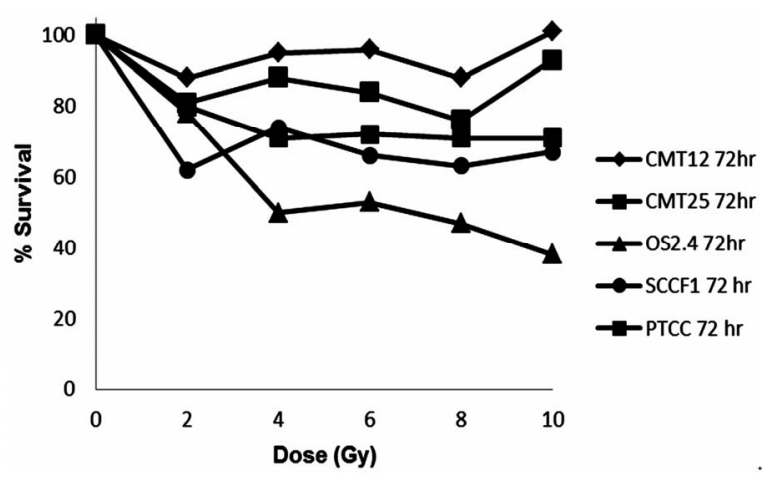

Figure 2. Dose of radiation versus \% surviving fraction (as measured by MTT assay) for the cancer cell lines CMT12, CMT25, OS2.4, SCCF1 and PTCC.

Table 1. The median combination index for cells exposed to docetaxel and radiation. Synergism CI $<0.7$; moderate synergism CI = 0.7 - 0.9; Additive effect $\mathrm{CI}=0.9$ - 1.1 .

\begin{tabular}{ccc}
\hline Cell Line & Median Combination Index $(\mathrm{CI})$ & Range \\
\hline CMT12 & 0.35 & $0.07-1.51$ \\
CMT25 & 0.47 & $0.06-5.20$ \\
OS2.4 & 0.63 & $0.02-3.22$ \\
SCCF1 & 0.76 & $0.06-3.62$ \\
PTCC & 2.75 & $0.25-121.72$ \\
\hline
\end{tabular}

dependent cytotoxic effect in all cell lines. In contrast, but not surprisingly, all cell lines studied were relatively resistant to the cytotoxic effects of single dose monotherapy up to the maximum 10 Gy radiation exposure studied. However, when these animal cancer cell lines were treated with the combination of docetaxel and radiation a synergistic cytotoxic effect was observed in canine mammary carcinoma (CMT-12 and CMT-25) cells and osteosarcoma cells (OS2.4). The studies on the feline squamous cell carcinoma cell line (SCCF1) revealed a moderate synergistic effect of the docetaxel-radiation combination, but somewhat surprisingly an antagonistic cytotoxic effect was noted in the transitional cell carcinoma cell line (PTCC).

In order for drugs to sensitize tumor cells to the cytotoxic effects of radiation increased cell kill needs to be either additive or synergistic using both modalities sequentially with a true clinical benefit only being achieved if the cytoxicity is greater to the tumor cells than to normal tissues. The observed additivity or synergism in these in vitro treatment models does not necessarily accurately predict the same results in vivo but provides a strong scientific rationale to perform a phase I clinical trial in veterinary patients with such cancers. Cellular radiosensitivity is dependent on the phase of the cell cycle cells are in, with cells in the $\mathrm{S}$ phase being most resistant to radiation damage and cells in the $\mathrm{G}_{2} \mathrm{M}$ phase of the cell cycle being most sensitive to radiation damage. Taxanes were shown in in vitro models to synchronize tumor cells in the $\mathrm{G}_{2} \mathrm{M}$ phase by forming high-affinity bonds with microtubules, promoting tubulin polymerization and stabilization thus facilitating greater sensitivity to the cytotoxic effects of radiation therapy. Additional mechanisms in vivo include the effects of tumor shrinkage which improves vascular perfusion and therefore oxygenation. As hypoxic regions of a tumor become better oxygenated they are more sensitive to the cytotoxic effects of radiation. Other postulated mechanisms of enhanced cytotoxicity when docetaxel and radiation are combined include inactivation of the anti-apoptotic protein Bcl-2 by phosphorylation and inhibition of angiogenesis [21,40-44].

For chemoradiotherapy to be effective in the patient there must be enhancement of the radiation response in the tumor that is greater than the enhancement of any local normal tissue toxicity thereby increasing the therapeutic index. In studies by Mason et al. [25] mice treated with intravenous docetaxel and radiation showed a potentiation of tumor radioresponse that was greater than the potentiation of jejunal crypt injury at all time points [25]. In this same study when intravenous docetaxel was given to mice 48 hours prior to a single dose of radiation there appeared to be a radioprotective effect on the jejunum. Clinical studies involving tumor bearing dogs and cats would be necessary to determine if the same effect was seen in this population.

The feline SCC cell line (SCCF1) treated with docetaxel resulted in dose dependent cytotoxicity and an overall moderate synergistic cytotoxicity when combined with radiation. However, at low fractions affected (which relate to the lower docetaxel concentrations studied, 0.01 $-0.1 \mu \mathrm{M})$ there was clearer evidence of synergistic cell kill when combined with radiation $(\mathrm{CI}=0.62)$. Cats with oral SCC often present late in the disease with non-resectable tumors either due to advanced local disease or tumors in locations not amenable to surgical resection. 
Docetaxel-RT CMT12 Cells 72h

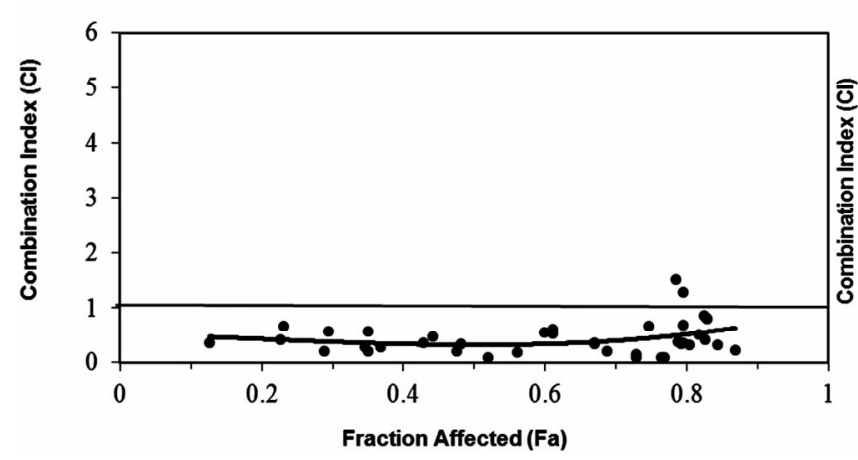

(a)

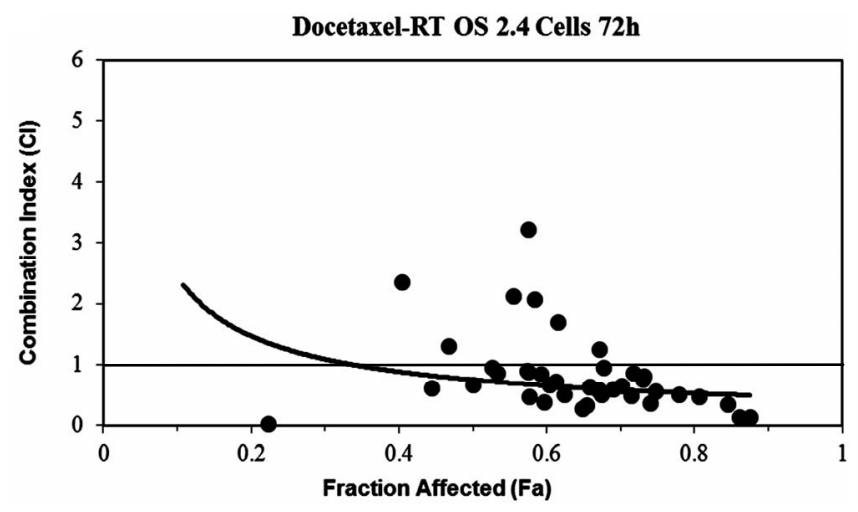

(c)
Docetaxel-RT CMT25 Cells 72h

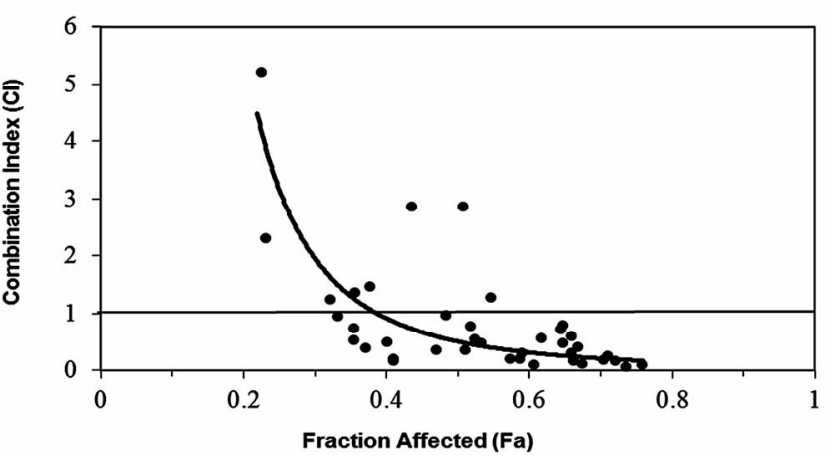

(b)

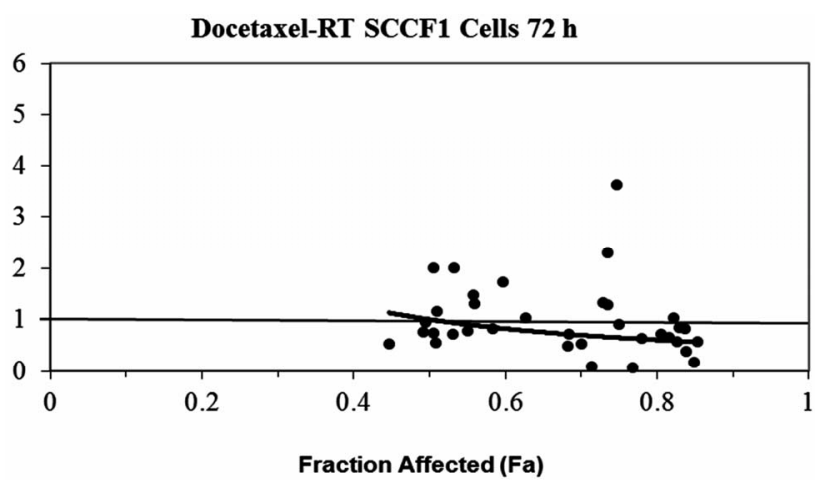

(d)

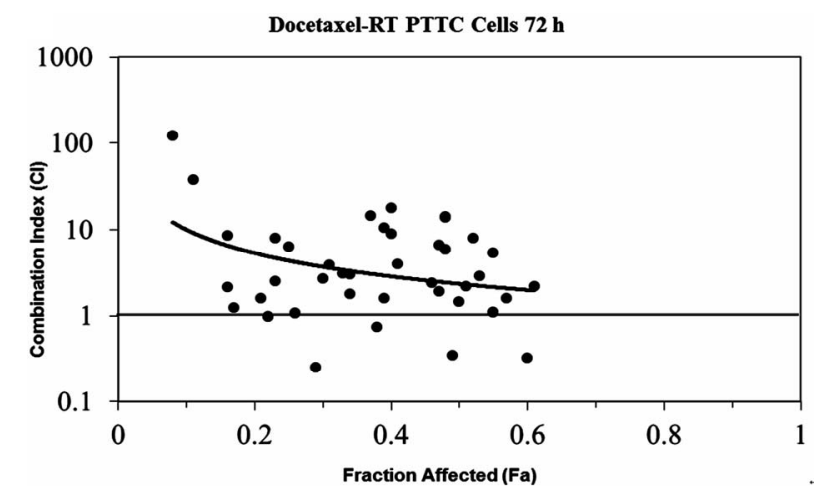

(e)

Figure 3. The plot of the modeled combination Index vs. fraction affected (cell death) for docetaxel combined with RT (a) CMT12 cells (b) CMT25 cells (c) OS2.4 cells (d) SCCF1 cells (e) PTCC cells-note the log scale for the CI in this cell line. The solid line at $\mathrm{CI}=1$ represents additivity. Values below this line indicate synergism, above this line indicate antagonism.

Therapy with either radiation or chemotherapy monotherapy has not improved survival times. Previous clinical studies evaluating gemcitabine as a radiation sensitizer in feline oral SCC revealed disappointing results with short disease free intervals or unexpected toxicity $[45,46]$. Studies in humans with head and neck squamous cell carcinoma have shown improved outcomes with the addition of docetaxel to multimodality therapy $[47,48]$. The results of the in vitro study presented here are en- couraging and further investigation of docetaxel as a radiation sensitizer for feline oral squamous cell carcinoma is therefore warranted.

The results of our in vitro studies generate hypotheses for further in vitro studies to determine the mechanism(s) of docetaxel radiosensitization in canine and feline tumor cell lines. Importantly the data also provide a strong scientific rationale for the development and performance of early clinical trials to determine the optimal dosing and 
schedule of docetaxel combined with radiation in tumor bearing dogs (with e.g. mammary carcinoma or osteosarcoma) and cats with oral squamous cell carcinoma.

\section{Conflict of Interest Statement}

None of the authors of this paper has a financial or personal relationship with other people or organizations that could inappropriately influence or bias the content of the paper.

\section{Acknowledgements}

This study was supported by Cornell University Dean's Fund for Clinical Excellence, and the Sprecher Institute for Comparative Cancer Research. LDL is supported in part by NCI P30 CA23108.

\section{REFERENCES}

[1] V. Bregazzi, S. M. LaRue, E. McNiel, D. W. Macy, W. S. Dernell, B. E. Powers and S. J. Withrow, "Treatment with a Combination of Doxorubicin, Surgery, and Radiation Versus Surgery and Radiation Alone for Cats with Vaccine-Associated Sarcoma: 25 Cases (1995-2000)," Journal of the American Veterinary Medical Association, Vol. 218, No. 4, 2001, pp. 547-550.

doi:10.2460/javma.2001.218.547

[2] T. Kobayashi, M. L. Hauck, R. Dodge, R. L. Page, G. S. Price, L. E. Williams, E. M. Hardie, K. G. Mathews and E. D. Thrall, "Preoperative Radiotherapy for Vaccine Associated Sarcoma in 92 Cats," Veterinary Radiology \& Ultrasound, Vol. 43, No. 5, 2002, pp. 473-479. doi:10.1111/j.1740-8261.2002.tb01036.x

[3] K. P. Freeman, K. A. Hahn, F. D. Harris and G. K. King, "Treatment of Dogs with Oral Melanoma by Hypofractionated Radiation Therapy and Platinum-Based Chemotherapy (1987-1997)," Journal of Veterinary Internal Medicine, Vol. 17, No. 1, 2003, pp. 96-101.

[4] M. M. Turek, L. J. Forrest, W. M. Adams, S. C. Helfand and D. M. Vail, "Postoperative Radiotherapy and Mitoxantrone for Anal Sac Adenocarcinomas in the Dog: 15 Cases (1991-2001)," Veterinary and Comparative Oncology, Vol. 1, No. 2, 2003, pp. 94-104. doi:10.1046/j.1476-5829.2003.00013.x

[5] S. E. Lana, W. S. Dernell, M. H. Lafferty, S. J. Withrow and S. M. LaRue, "Use of Radiation and a Slow-Release Cisplatin Formulation for Treatment of Canine Nasal Tumors," Veterinary Radiology \& Ultrasound, Vol. 45, No. 6, 2004, pp. 577-581. doi:10.1111/j.1740-8261.2004.04100.x

[6] M. E. Nadeau, B. E. Kitchell, R. L. Rooks and S. M. LaRue, "Cobalt Radiation with or Without Low-Dose Cisplatin for Treatment of Canine Naso-Sinus Carcinomas," Veterinary Radiology \& Ultrasound, Vol. 45, No. 4, 2004, pp. 362-367. doi:10.1111/j.1740-8261.2004.04068.x

[7] K. A. Hahn, M. N. Endicott, G. K. King and F. D. Har-
ris-King, "Evaluation of Radiotherapy Alone or in Combination with Doxorubicin Chemotherapy for the Treatment of Cats with Incompletely Excised Soft Tissue Sarcomas: 71 Cases (1989-1999)," Journal of the American Veterinary Medical Association, Vol. 231, No. 5, 2007, pp. 742-745. doi:10.2460/javma.231.5.742

[8] D. Simon D, J. W. Knebel, W. Baumgärtner, M. Aufderheide, A. Meyer-Lindenberg and I. Nolte, "In Vitro Efficacy of Chemotherapeutics as Determined by $50 \%$ Inhibitory Concentrations in Cell Cultures of Mammary Gland Tumors Obtained from Dogs," American Journal of Veterinary Research, Vol. 62, No. 11, 2001, pp. 18251830. doi:10.2460/ajvr.2001.62.1825

[9] L. E. Williams, N. Banerji, J. S. Klausner, V. Kapur and S. Kanjilal, "Establishment of Two Vaccine-Associated Feline Sarcoma Cell Lines and Determination of in Vitro Chemosensitivity to Doxorubicin and Mitoxantrone," American Journal of Veterinary Research, Vol. 62, No. 9, 2001, pp. 1354-1357. doi:10.2460/ajvr.2001.62.1354

[10] N. Banerji, X. Li, J. S. Klausner, V. Kapur and S. Kanjilal, "Evaluation of in Vitro Chemosensitivity of VaccineAssociated Feline Sarcoma Cell Lines to Vincristine and Paclitaxel," American Journal of Veterinary Research, Vol. 63, No. 5, 2002, pp. 728-732. doi:10.2460/ajvr.2002.63.728

[11] R. Katayama, M. K. Huelsmeyer, A. K. Marr, I. D. Kurzman, D. H. Thamm and D. M. Vail, "Imatinib Mesylate Inhibits Platelet-Derived Growth Factor Activity and Increases Chemosensitivity in Feline Vaccine-Associated Sarcoma," Cancer Chemotherapy and Pharmacology, Vol. 54, No. 1, 2004, pp. 25-33. doi:10.1007/s00280-004-0780-7

[12] S. D. Hafeman, D. Varland and S. W. Dow, "Bisphosphonates Significantly Increase the Activity of Doxorubicin or Vincristine against Canine Malignant Histiocytosis Cells," Veterinary and Comparative Oncology, Vol. 10, No. 1, 2011, pp. 44-56. doi:10.1111/j.1476-5829.2011.00274.x

[13] N. K. Thudi, S. T. Shu, C. K. Martin, L. G. Lanigan, M. V. P. Nadella, A. Van Bokhoven, J. L. Webeck, J. K. Simmons, S. Murahari, W. C. Kisseberth, M. Breen, C. Williams, C. S. Chen, L. K. McCauley, E. T. Keller and T. J. Rosol, "Development of a Brain Metastatic Canine Prostate Cancer Cell Line," The Prostate, Vol. 71, No. 12, 2011, pp. 1251-1263.

[14] F. Lavelle, M. C. Bissery, C. Combeau, J. F. Riou, P. Vrignaud and S. André, "Preclinical Evaluation of Docetaxel (Taxotere)," Seminars in Oncology, Vol. 22, No. 6 Suppl. 13, 1995, pp. 3-16.

[15] A. L. Dunne, C. Mothersill, T. Robson, G. D. Wilson and D. G. Hirst, "Radiosensitization of Colon Cancer Cell Lines by Docetaxel: Mechanisms of Action," Oncology Research, Vol. 14, No. 9, 2004, pp. 447-454.

[16] G. P. Amorino, V. M. Hamilton and H. Choy, " Enhancement of Radiation Effects by Combined Docetaxel and Carboplatin Treatment in Vitro," Radiation Oncology Investigations, Vol. 7, No. 6, 1999, pp. 343-352 doi:10.1002/(SICI)1520-6823(1999)7:6<343::AID-ROI4 3.0.CO;2-C 
[17] H. L. Lin, T. Y. Liu, G. Y. Chau, W. Y. Liu and C. W. Chi, "Comparison of 2-Methoxyestradiol-Induced, Docetaxel-Induced, and Paclitaxel-Induced Apoptosis in Hepatoma Cells and Its Correlation with Reactive Oxygen Species," Cancer, Vol. 89, No. 5, 2000, pp. 983-994. doi:10.1002/1097-0142(20000901)89:5<983::AID-CNCR $7>3.0 . \mathrm{CO} ; 2-\mathrm{G}$

[18] D. R. Budman and A. Calabro, "In Vitro Search for Synergy and Antagonism: Evaluation of Docetaxel Combinations in Breast Cancer Cell Lines," Breast Cancer Research and Treatments, Vol. 74, No. 1, 2002, pp. 41-46. doi:10.1023/A:1016070230538

[19] L. Milas, M. M. Milas and K. A. Mason, "Combination of Taxanes with Radiation: Preclinical Studies," Seminars in Radiation Oncology, Vol. 9, No. 2, 1999, pp. 12-26.

[20] L. Milas, "Docetaxel/Radiation Combinations: Rationale and Preclinical Findings," Clinical Lung Cancer, Vol. 3, Suppl. 2, 2002, pp. S29-S36.

[21] D. S. Grant, T. L. Williams, M. Zahaczewsky and A. P. Dicker, "Comparison of Antiangiogenic Activities Using Paclitaxel (Taxol) and Docetaxel (Taxotere)," International Journal of Cancer, Vol. 104, No. 1, 2003, pp. 121129. doi:10.1002/ijc.10907

[22] T. W. Synold, I. Dussault and B. M. Forman, "The Orphan Nuclear Receptor SXR Coordinately Regulates Drug Metabolism and Efflux," Nature Medicine, Vol. 7, No. 5, 2001, pp. 584-590. doi:10.1038/87912

[23] C. Hennequin, N. Giocanti and V. Frenette, "Interaction of Ionizing Radiation with Paclitaxel (Taxol) and Docetaxel (Taxotere) in HeLa and SQ20B Cells," Cancer Research, Vol. 56, No. 8, 1996, pp. 1842-1850.

[24] O. Pradier, M. Rave-Frank, J. Lehmann, E. Lücke, O. Boghun, C. F. Hess and H. Schmidberger, "Effects of Docetaxel in Combination with Radiation on Human Head and Neck Cancer Cells (ZMK-1) and Cervical Squamous Cell Carcinoma Cells (CASKI)," International Journal of Cancer, Vol. 91, No. 6, 2001, pp. 840-845. doi:10.1002/1097-0215(200002)9999:9999<::AID-IJC11 $\underline{42>3.0 . \mathrm{CO} ; 2-\mathrm{U}}$

[25] K. A. Mason, N. R. Hunter, M. Milas, J. L. Abbruzzese and L. Milas, "Docetaxel Enhances Tumor Radioresponse in Vivo," Clinical Cancer Research, Vol. 3, No. 12, 1997, pp. 2431-2438.

[26] K. A. Mason, K. Kishi, N. Hunter, L. Buchmiller, T. Akimoto, R. Kumaki and L. Milas, "Effect of Docetaxel on the Therapeutic Ratio of Fractionated Radiotherapy in Vivo," Clinical Cancer Research, Vol. 5, No. 12, 1999, pp. 4191-4198.

[27] R. B. Tishler, C. M. Norris, A. D. Colevas, C. C. Lamb, D. Karp, P. M. Busse, A. Nixon, B. Lake-Willcutt, R. Costello, M. Case and M. R. Posner, "A Phase I/II Trial of Concurrent Docetaxel and Radiation After Induction Chemotherapy in Patients with Poor Prognosis Squamous Cell Carcinoma of the Head and Neck," Cancer, Vol. 95, No. 7, 2002, pp. 1472-1481. doi:10.1016/S0360-3016(03)01370-1

[28] G. Calais, E. Bardet, C. Sire, M. Alfonsi, J. Bourhis, B. Rhein, J. Tortochaux, Y. T. Man, H. Auvray and P. Garaud, "Radiotherapy with Concomitant Weekly Docetaxel for Stages III/IV Oropharynx Carcinoma. Results of the 98-02 Gortec Phase II Trial," International Journal of Radiation Oncology Biology and Physics, Vol. 58, No. 1, 2004, pp. 161-166. doi:10.1016/S0360-3016(03)01370-1

[29] S. D. Baker, M. Zhao, C. K. Lee, J. Verweij, Y. Zabelina, J. R. Brahmer, A. C. Wolff, A. Sparreboom and M. A. Carducci, "Comparative Pharmacokinetics of Weekly and Every-Three-Week Docetaxel," Clinical Cancer Research, Vol. 10, No. 6, 2004, pp. 1976-1983. doi:10.1158/1078-0432.CCR-0842-03

[30] P. Kumar, M. Perrotti, R. Weiss, M. Todd, S. Goodin, K. Cummings and R. S. DiPaola, "Phase I Trial of Weekly Docetaxel with Concurrent Three-Dimensional Conformal Radiation Therapy in the Treatment of Unfavorable Localized Adenocarcinoma of the Prostate," Journal of Clinical Oncology, Vol. 22, No. 10, 2004, pp. 1909-1915. doi:10.1200/JCO.2004.02.001

[31] M. Fujii, M. Tsukuda, B. Satake, A. Kubota, A. Kida, N. Kohno, K. Okani and Y. Inuyama, "Phase I/II Trial of Weekly Docetaxel and Concomitant Radiotherapy for Squamous Cell Carcinoma of the Head and Neck," International Journal of Clinical Oncology, Vol. 9, No. 2, 2004, pp. 107-112. doi:10.1007/s10147-003-0375-Z

[32] A. F. Kovács, S. Mose, H. D. Böttcher and K. Bitter, "Multimodality Treatment Including Postoperative Radiation and Concurrent Chemotherapy with Weekly Docetaxel Is Feasible and Effective in Patients with Oral and Oropharyngeal Cancer," Strahlentherapie und Onkologie, Vol. 181, No. 1, 2005, pp. 26-34. doi:10.1007/s00066-005-1272-3

[33] A. Barnadas, R. Mesía, M. Majem, R. Galiana, A. LópezPousa, J. M. de Vega, M. Margelí, V. Valentí, L. Anglada, A. Lloansí and A. Arellano, "Phase I/II Docetaxel Plus Concurrent Hyperfractionated Radiotherapy in Locally Advanced Unresectable Head and Neck Cancer," Clinical \& Translational Oncology, Vol. 13, No. 4, 2011, pp. 254260.

[34] M. C. McEntee, K. M. Rassnick, L. D. Lewis, M. M. Zgola, B. B. Beaulieu, C. E. Balkman and R. L. Page, "Phase I and Pharmacokinetic Evaluation of Oral Docetaxel and Cyclosporin A in Tumor-Bearing Dogs," American Journal of Veterinary Research, Vol. 67, No. 6, 2006, pp. 1057-1062. doi:10.2460/ajvr.67.6.1057

[35] M. C. McEntee, K. M. Rassnick, D. B. Bailey, C. E. Balkman, J. L. Flanagan, B. B. Beaulieu, M. M. Zgola, L. D. Lewis and R. L. Page, "Phase I and Pharmacokinetic Evaluation of the Combination of Orally Administered Docetaxel and Cyclosporin A in Tumor-Bearing Cats," Journal of Veterinary Internal Medicine, Vol. 20, No. 6, 2006, pp. 1370-1375. doi:10.1111/j.1939-1676.2006.tb00753.x

[36] A. Waite, C. Balkman, D. Bailey, M. Kiselow, A. Flory, B. Beaulieu, L. Lewis and M. McEntee, "Phase II Study of Oral Docetaxel and Cyclosporine in Canine Epithelial Cancer," Veterinary and Comparative Oncology, 2012, (in Press). doi:10.1111/j.1476-5829.2012.00350.x

[37] T. C. Chou and P. Talalay, "Quantitative Analysis of Dose-Effect Relationships: The Combined Effects of Multiple Drugs or Enzyme Inhibitors," Advances in En- 
zyme Regulation, Vol. 22, 1984, pp. 27-55. doi:10.1016/0065-2571(84)90007-4

[38] C. E. Leonard, D. C. Chan, T. C. Chou, R. Kumar and P. A. Bunn, "Paclitaxel Enhances in Vitro Radiosensitivity of Squamous Carcinoma Cell Lines of the Head and Neck," Cancer Research, Vol. 56, No. 22, 1996, pp. 51985204.

[39] T. C. Chou, "The Median-Effect Principle and the Combination Index for Quantitation of Synergism and Antagonism," In: T. C. Chou and D. C. Rideout, Eds., Synergism and Antagonism in Chemotherapy, Academic Press, San Diego, 1991, pp. 61-102.

[40] S. Haldar, A. Basu and C. M. Croce, "Bcl-2 Is the Guardian of Microtubule Integrity," Cancer Research, Vol. 57, No. 2, 1997, pp. 229-233.

[41] C. J. Sweeny, K. D. Miller, S. E. Sissons, S. Nozaki, D. K. Heilman, J. Shen and G. W. Sledge, "The Antiangiogenic Property of Docetaxel Is Synergistic with A Recombinant Humanized Monoclonal Antibody against Vascular Endothelial Growth Factor or 2-Methoxyestradiol but Antagonized by Endothelial Growth Factors," Cancer Research, Vol. 61, No. 8, 2001, pp. 3369-3372.

[42] A. Vacca, D. Ribatti, M. Iurlaro, F. Merchionne, B. Nico, R. Ria and F. Dammacco, "Docetaxel Versus Paclitaxel for Antiangiogenesis," Journal of Hematotherapy \& Stem Cell Research, Vol. 11, No. 1, 2002, pp. 103-118. doi:10.1089/152581602753448577

[43] K. A. Hotchkiss, A. W. Ashton, R. Mahmood, R. G. Russell, J. A. Sparano and E. L. Schwartz, "Inhibition of Endothelial Cell Function in Vitro and Angiogenesis in Vivo by Docetaxel (Taxotere): Association with Impaired Repositioning of the Microtubule Organizing Center," Molecular Cancer Therapeutics, Vol. 1, No. 13, 2002, pp. 1191-1200.

[44] M. Muta, T. Yanagawa, Y. Sai Y, S. Saji, E. Suzuki, T. Aruga, K. Kuroi, G. Matsumoto, M. Toi and E. Naka- shima, "Effect of Low-Dose Paclitaxel and Docetaxel on Endothelial Progenitor Cells," Oncology, Vol. 77, No. 3-4, 2009, pp. 182-191. doi:10.1159/000236016

[45] P. D. Jones, L. P. de Lorimier, B. E. Kitchell and J. M. Losonsky, "Gemcitabine as a Radiosensitizer for Nonresectable Feline Oral Squamous Cell Carcinoma," Journal of the American Animal Hospital Association, Vol. 39, No. 5, 2003, pp. 463-467.

[46] A. K. LeBlanc, T. A. LaDue, J. M. Turrel and M. K. Klein, "Unexpected Toxicity Following Use of Gemcitabine as a Radiosensitizer in Head and Neck Carcinomas: A Veterinary Radiation Therapy Oncology Group Pilot Study," Veterinary Radiology \& Ultrasound, Vol. 45, No. 5, 2004, pp. 466-470. doi:10.1111/j.1740-8261.2004.04080.x

[47] M. R. Posner, D. M. Hershock, C. R. Biajman, E. Mickiewicz, E. Winquist, V. Gorbounova, S. Tjulandin, D. M. Shin, K. Cullen, T. J. Ervin, B. A. Murphy, L. E. Raez, R. B. Cohen, M. Spaulding, R. B. Tishler, B. Roth, R. D. C. Viroglio, V. Venkatesan, I. Ramanov, S. Agarwala, K. W. Harter, M. Dugan, A. Cmelak, A. M. Markoe, P. W. Read, L. Steinbrenner, D. Colevas, C. M. Norris and R. I. Haddad, "Cisplatin and Fluorouracil Alone or with Docetaxel in Head and Neck Cancer," The New England Journal of Medicine, Vol. 357, No. 17, 2007, pp. 1705-1715. doi:10.1056/NEJMoa070956

[48] M. Tsukuda, J. Ishitoya, H. Matsuda, C. Horiuchi, T. Taguchi, M. Takahashi, G. Nashimura, M. Kawakami, M. Watanabe, T. Niho, T. Kawano, Y. Ikeda, Y. Sakuma, O. Shiono and M. Komatsu, "Randomized Controlled Phase II Comparison Study of Concurrent Chemoradiotherapy with Docetaxel, Cisplatin, and 5-Fluorouracil versus CCRT with Cisplatin, 5-Fluorouracil, Methotrexate and Leucovorin in Patients with Locally Advanced Squamous Cell Carcinoma of the Head and Neck," Cancer Chemotherapy and Pharmacology, Vol. 66, No. 4, 2010, pp. 729736. doi:10.1007/s00280-009-1217-0 